Article

\title{
Experimental Observation of Natural Convection Heat Transfer Performance of a Rectangular Thermosyphon
}

\author{
C. S. Huang ${ }^{1}$, Chia-Wang Yu ${ }^{2}$, R. H. Chen ${ }^{3}$, Chun-Ta Tzeng ${ }^{2}$ and Chi-Ming Lai ${ }^{4, *(D)}$ \\ 1 Department of Mechanical Engineering, Southern Taiwan University of Science and Technology, \\ Tainan 710, Taiwan; huang.c.s1018@gmail.com \\ 2 Department of Architecture, National Cheng Kung University, Tainan 701, Taiwan; \\ jiawang_yu@hotmail.com (C.-W.Y.); ctmt@mail.ncku.edu.tw (C.-T.T.) \\ 3 Department of Mechanical and Energy Engineering, National Chiayi University, Chiayi 600, Taiwan; \\ chenrh@mail.ncyu.edu.tw \\ 4 Department of Civil Engineering, National Cheng Kung University, Tainan 701, Taiwan \\ * Correspondence: cmlai@mail.ncku.edu.tw; Tel.: +886-6-2757575
}

Received: 8 March 2019; Accepted: 3 May 2019; Published: 6 May 2019

\begin{abstract}
This study experimentally investigates the natural convection heat transfer performance of a rectangular thermosyphon with an aspect ratio of 3.5. The experimental model is divided into a loop body, a heating section, a cooling section, and two adiabatic sections. The heating section and the cooling section are located in the vertical legs of the rectangular loop. The length of the vertical heating section and the length of the upper and lower horizontal insulation sections are $700 \mathrm{~mm}$ and $200 \mathrm{~mm}$, respectively, and the inner diameter of the loop is $11 \mathrm{~mm}$. The relevant parameters and their ranges are as follows: the input thermal power is 30-60 W (with a heat flux in the range of $60-3800 \mathrm{~W} / \mathrm{m}^{2}$ ); the temperature in the cooling section is 30,40 , or $50{ }^{\circ} \mathrm{C}$; and the potential difference between the hot and cold sections is 5,11, or 18 for the cooling section lengths of 60,45 , and $30 \mathrm{~cm}$, respectively. The results indicate that the value of the dimensionless heat transfer coefficient, the Nusselt number, is generally between 5 and 10. The heating power is the main factor affecting the natural convection intensity of the thermosyphon.
\end{abstract}

Keywords: heat transfer; energy; thermosyphon; natural circulation loop

\section{Introduction}

A thermosyphon is a type of natural convection loop. By proper arrangement of the heating zone and the cooling zone, the fluid in the loop changes in density, and the resulting thermal buoyancy drives the heat transfer of the working fluid. The cooling section and the heating section are usually placed on the upper and lower sides or on the left and right sides of the loop, respectively. Heating of the working fluid produces a lower density, which generates thermal buoyancy and upward flow, and the heat is radiated toward the cooling section. Gravity works against the working fluid as it flows upwards and assists it as it flows downward (i.e., in the same direction as the gravity). Because there is no need for an external driving force, a thermosyphon has considerable operational reliability. The self-adjusting mechanism and stability enable thermosyphons to be applied in an extensive range of applications, such as solar heating and cooling systems, coolers for reactors in nuclear power plants, geothermal energy systems, waste heat recovery systems, and electronic cooling systems. There are many considerations when designing a thermosyphon with good thermal efficiency, such as the choice of working fluid, the choice of wall material, the location of the heating and cooling sections, and the geometry of the loop [1-10]. 
Garrity et al. [1] studied the instability of a two-phase thermosiphon with a microchannel evaporator and a condenser. Vijayan et al. [2] analyzed the steady state and stability of single-phase, two-phase, and supercritical natural convection in a rectangular loop using a 1-D theoretical model. Misale et al. [3] analyzed the influence of the thermal boundary conditions on the flow regimes inside the pipes and the stability of the thermosiphon. The results indicated that the larger the heating power is, the larger the flow rate; however, after becoming a two-phase flow, the flow rate is reduced due to the generation of bubbles. Lai et al. [4] explored the influences of the aspect ratio, potential difference, heating power, and cooling temperature on the thermal performance of a rectangular natural circulation loop. Delgado et al. [5] reviewed the information and application of two latent working fluids: phase change material (PCM) emulsions and microencapsulated PCM slurries.

Desrayaud et al. [6] numerically investigated the instability of a rectangular natural circulation loop with horizontal heat exchanging sections for various Rayleigh number (Ra) values. The results show that vortices induce the occurrence of oscillations and the growth of temperature gradients. Buschmann [7] analyzed the research on thermosyphons, heat pipes, and oscillating heat pipes operated with nanofluids based on 38 experimental studies and 4 modeling approaches. The results show that the effects related to the filling ratio, inclination angle, and operation temperature seem to be similar to those for classical working fluids. Huminic [8] investigated the effects of volume concentrations of nanoparticles and the operating temperature on the heat transfer performance of a thermosyphon heat pipe with nanofluids using a three-dimensional simulation. The results show that the volume concentration of nanoparticles significantly reduced the temperature difference between the evaporator and the condenser. Sureshkumar et al. [9] reviewed and summarized an improvement in the thermal efficiency and the thermal resistance of heat pipes with nanofluids. Gupta et al. [10] presented an overview of the heat transfer mechanisms of heat pipes in terms of thermal performance.

Ho et al. [11] obtained the relation of the Ra with the Reynolds number (Re) and Nusselt number $(\mathrm{Nu})$ of a single-phase thermosyphon through experiments and numerical simulations. Vijayan et al. [12] studied the effect of the heater and cooler orientations on a single-phase thermosyphon. Three oscillatory modes and instabilities were observed in the experiments. Misale et al. [13] tested a thermosyphon with different tilting angles and found that the tilt angle affects the heat transfer effect, and the best effect was obtained with a tilt angle of $0^{\circ}$ (vertical to the ground). Swapnalee and Vijayan [14] obtained the relationship formula between the Re and Gr through experiments and simulations of single-phase flow in a thermosyphon and used the geometric parameter $\mathrm{N}_{\mathrm{g}}$ to modify the $\mathrm{Gr}$, crafting a prediction model that was applicable in four different heating and cooling modes. Thomas and Sobhan [15] experimentally studied the stability and transient performance of a vertical heater-cooler natural circulation loop with metal oxide nanoparticles. Their results indicate that nanofluids containing aluminum oxide and copper oxide have superior heat transfer performances than pure water as the working fluid.

Because the literature on heating and cooling sections positioned in the two vertical sections of a rectangular thermosyphon is quite limited, despite the high potential of this application, this paper explores the natural convection heat transfer phenomenon of a rectangular thermosyphon with a geometric aspect ratio of 3.5. The boundary conditions of the loop heating section and the cooling section feature a fixed heat flux and a fixed wall temperature, respectively.

\section{Materials and Methods}

\subsection{Scenarios and Test Cell Development}

We aim to develop a structure that can harvest solar heat while attached to a metal wall (Figure 1a). In addition to extracting heat energy, this building façade prototype can also effectively buffer the heat of the sun. Therefore, an energy-harvesting façade, as part of a solar thermal system and integrated with the building envelope structure, has been developed. To simplify the boundary conditions, we simplified the prototype into a rectangular natural circulation loop to further explore its basic heat flow mode and thermal performance. 


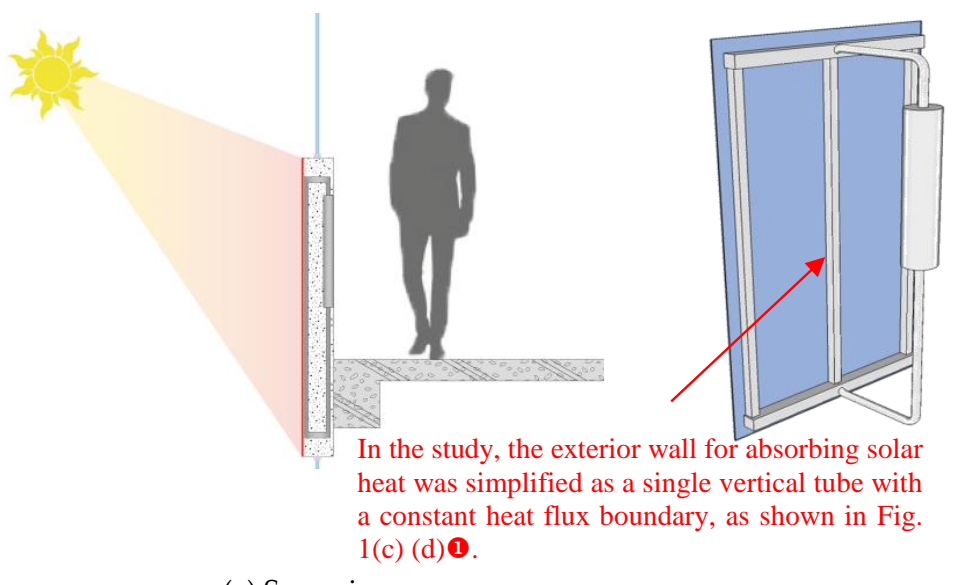

$\begin{array}{ll}\text { (a) Scenario } & \text { (b) Prototype }\end{array}$

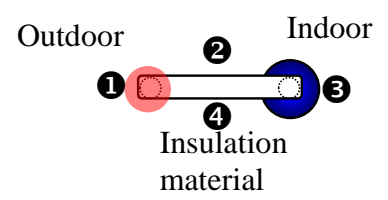

(c) Vertical view of the test cell

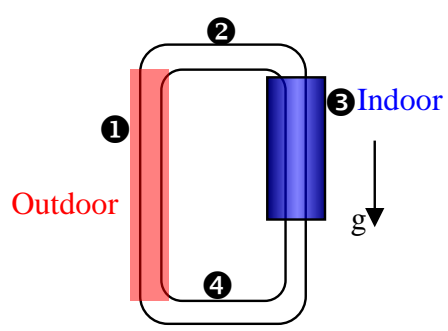

(d) Side view of the test cell

Figure 1. Scenario, prototype development, and test cell illustration.

The prototype design is shown in Figure 1b. To simplify the boundary conditions and observe the basic heat flow performance, we simplified the prototype to the experimental test cell shown in Figure $1 \mathrm{c}, \mathrm{d}$. The heat absorbing wall panel shown in Figure $1 \mathrm{~b}$ is first simplified to a boundary with a constant heat flux, as shown by in Figure 1c,d. The vertical view in Figure 1c shows the components without the insulation above the device for easy viewing. The side view in Figure $1 \mathrm{~d}$ shows the components without the heat insulation materials filling the space between the exterior wall and the interior wall to clearly illustrate the components of the circulation loop.

During the day, the working fluid in the circulation loop becomes a high-temperature fluid after absorbing heat from the outdoor heat source $\mathbf{0}$. Driven by thermal buoyancy, the fluid forms natural convection, circulates along the horizontal circulation branch 2 to the indoor heat sink, dissipates heat in the indoor heat $\operatorname{sink} \boldsymbol{3}$, and flows back to the outdoor heat source by another horizontal circulation branch 4 via gravity; thus, a naturally flowing natural circulation loop is formed. The outdoor heat source is represented by a heated vertical tube; the indoor heat sink $\mathbf{3}$ is a vertical section of an isothermal boundary.

\subsection{Experimental Test Cell}

The experimental test cell can be divided into a rectangular loop comprising a heating section, a cooling section, and two adiabatic sections. The heating section and the cooling section are both located in the vertical portions of the loop (Figure 2) and are described below.

\subsubsection{The Rectangular Loop}

The loop components in this test cell are all red brass tubes with high thermal conductivity, and the entire loop in the test cell has the same cross-sectional area, resulting in a constant tube flow value. The red brass tubes have an outer diameter of $12.7 \mathrm{~mm}$ and an inner diameter $\left(D_{i}\right)$ of $11 \mathrm{~mm}$. The length of the vertical heating section (Ly) is $700 \mathrm{~mm}$, and the lengths (Lx) of the upper and lower adiabatic sections of the experimental test cell are both $200 \mathrm{~mm}$; thus, the aspect ratio AR (=Ly/Lx) of the test cell is 3.5. To investigate the influence of the geometry of the experimental test cell on the heat transfer capability of the system, we set the cooling end length Lc to 30, 45, and $60 \mathrm{~cm}$, as shown in Figure $2 a-c$. The resulting potential differences $\left(\Delta Z=\frac{1}{2}\left(\frac{L_{y}-L_{c}}{D_{i}}\right)\right.$ are 18,11 , and 5 , respectively. 


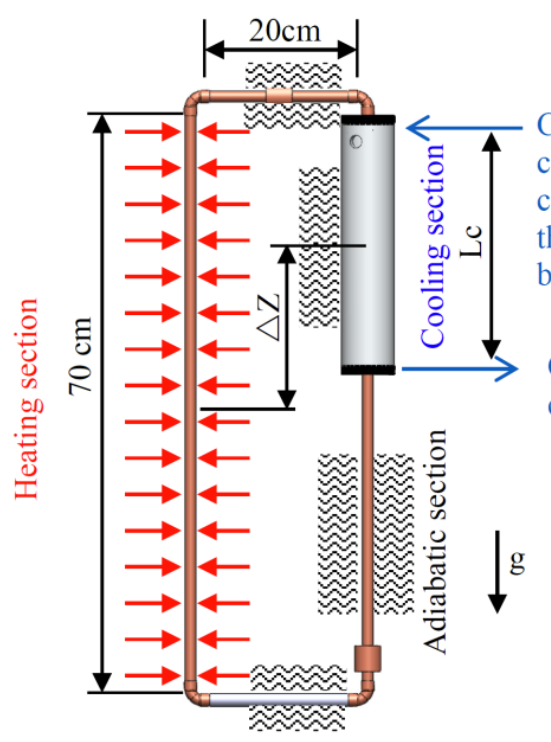

(a) $\mathrm{Lc}=30 \mathrm{~cm}(\triangle \mathrm{Z}=18)$

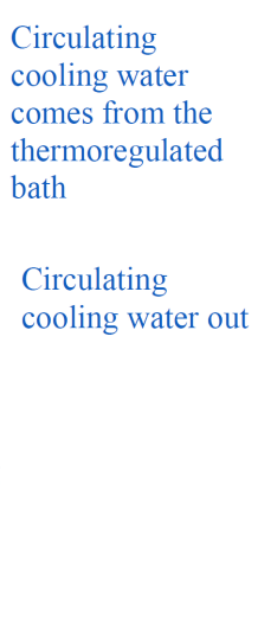

Circulating
cooling water out

(2) 12

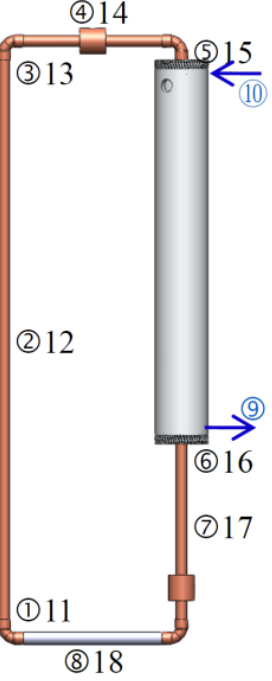

(b) $\mathrm{Lc}=45 \mathrm{~cm}(\triangle \mathrm{Z}=11)$

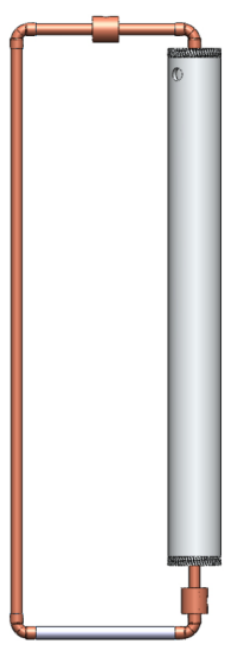

(c) $\mathrm{Lc}=60 \mathrm{~cm}(\triangle \mathrm{Z}=5)$

Figure 2. Experimental test cell and geometric parameters.

\subsubsection{Heating Section}

The heating section is a boundary with a constant heat flux that simulates the practical application, and therefore, heating wire is used to generate heating at a fixed power. To increase the uniformity of the heating section, the electric wire is directly processed into the heating section, which is mainly composed of muscovite paper, electric heating wire and heat insulation materials. Because the tube material of the experimental test cell is conductive red brass, we must insulate the surface of the heating section tube before winding the heating wire around the heating section. Therefore, the soft muscovite paper, which is an excellent insulator and heat-resistant to $500-550{ }^{\circ} \mathrm{C}$, is wound on the heating section for insulation purposes. The input electric power and the maximum voltage of the power supply are $60 \mathrm{~W}$ and $60 \mathrm{~V}$, respectively, so the resistance is $60 \Omega$. Therefore, this experiment selects a heating wire with a resistance close to $60 \Omega$. The heating wire is $2.5 \mathrm{~m}$ in length, $0.25 \mathrm{~mm}$ in diameter, and $25.82 \Omega / \mathrm{m}$ in resistance per unit length.

\subsubsection{Cooling Section}

The cooling section is a simulated isothermal boundary condition. To test the effects of different height differences between the hot and cold ends, the water sleeve is set to lengths of 300,450, and $600 \mathrm{~mm}$. The cooling water sleeve is mainly composed of a water sleeve body and a water sleeve cover. The water sleeve body is a cylinder with an outer diameter of $61 \mathrm{~mm}$ and an inner diameter of $40 \mathrm{~mm}$. Both ends of the water sleeve are water sleeve covers, and the center of each water sleeve cover has a hole that is approximately $11 \mathrm{~mm}$ in diameter. The thermosyphon passes through the holes in the cooling water sleeve, and the joints are fitted with O-ring grooves to prevent water leakage from the cooling water sleeve.

\subsubsection{Insulation Materials}

Except for the heating section and the cooling section, the remaining sections are adiabatic. To eliminate the effects of the external environment and heat loss during the experiment, 3-mm-thick insulating tape and a 40-mm-thick insulation pipe are wrapped around the body to effectively simulate adiabatic boundaries. 


\subsection{Experimental Apparatus}

The device and data acquisition system includes a data acquisition unit (Yokogawa MX-100, Tokyo, Japan), PC, a flow meter (Fluidwell F110-P, Veghel, The Netherlands), a DC power supply unit (Gwinstek SPD-3606, New Taipei City, Taiwan), and a thermoregulated bath (RCB-412, New Taipei City, Taiwan).

\subsubsection{Power Supply System}

The heating wire of the heating section is connected directly to the power supply (Gwinstek SPD-3606); the output voltage and current are adjusted to provide an input power $q_{h}$ of 30-60 W, as required in the experiment.

\subsubsection{Thermoregulated Bath}

The isothermal boundary of the cooling section is established by circulating water from a thermoregulated water bath (RCB412) to establish the cooling section temperature $\mathrm{Tc}_{\mathrm{c}}\left(30,40\right.$, or $\left.50^{\circ} \mathrm{C}\right)$ required for the experiment.

\subsubsection{Liquid Flow Meter}

A flow meter (F110-P; Fluidwell) is used to monitor the amount of cooling water sent by the thermostatic water tanks in each test, with an average flow rate of approximately $35 \mathrm{~mL} / \mathrm{s}$.

\subsubsection{Thermocouples}

This study uses type-K thermocouples to measure the wall temperature and the fluid temperature along the loop. There are 17 thermocouple points embedded in each experimental test cell at the upper, middle, and lower positions of the heating section, at the inlet and outlet of the water sleeve in the cooling section, and along the adiabatic sections. The thermocouple points are shown in Figure $2 \mathrm{~b}$. The thermocouple points numbered (1)-(8) measure the temperatures at the center point of the fluid in the tube; the thermocouple points numbered (9) and (10) measure the inlet and outlet water temperatures of the cooling sleeve; and the thermocouple points numbered 11-17 measure the temperatures of the outer tube wall.

\subsection{Parameters}

The relevant heat transfer parameters were calculated from the temperature measured by each thermocouple in the experimental test cell and the voltage and current supplied to the electric heating wire.

1. The input power $q_{h}=\mathrm{VI}$ can be obtained from the voltage V and the current I supplied by the power supply. Thus, the heat flux $q_{f l u x}$ is $q_{h} /$ A. During the experiment, the heating from the power supply is not completely transferred to the fluid in the heating section. A small amount of heat enters the cooling section via axial heat conduction $q_{a}$ in the loop body or escapes into the environment, so the axial heat transfer $q_{a}$ must be deducted from the input thermal power first. Therefore, the corrected actual input thermal power is $q_{i n}=q_{h}-q_{a}$.

2. Modified Rayleigh number, $\mathrm{Ra}^{*}$

$$
R a^{*}=\frac{g \beta\left(\frac{q_{i n}}{A} \frac{R_{i}}{k}\right) L_{y} D_{i}^{2}}{\alpha v}
$$

3. Parameters of the working fluid

(1) Flow rate of the working fluid $(\dot{V})$ The temperature of the fluid in the rectangular loop increases in the heating section, causing the fluid to flow to the cooling section by convection. The flow rate of this flow varies depending on the amount of thermal power input to the heating section and the cooling conditions in the cooling section. In this 
experiment, the input heat power $\left(q_{\text {in }}\right)$ and temperature difference $\left(\Delta T=T_{3}-T_{1}\right)$ were used to determine the fluid flow rate in the tube.

$$
\dot{V}=\frac{q_{\text {in }}}{\rho C_{p} A \Delta T}
$$

(2) Reynolds number, Re

$$
\operatorname{Re}=\frac{\dot{V}\left(2 R_{i}\right)}{v}
$$

4. Nusselt number

(1) The average heat transfer coefficient of the cooling end is:

$$
\bar{h}=\frac{q_{c} / A}{\overline{T_{w}}-\overline{T_{c}}}
$$

(2) The calculation of the $\mathrm{Nu}$ is as follows:

$$
\overline{\mathrm{Nu}}=\frac{\bar{h}\left(2 R_{i}\right)}{k}
$$

\subsection{Experimental Uncertainty}

The uncertainties in the measured quantities of this study were estimated to be $\pm 0.1^{\circ} \mathrm{C}$ for temperature, $\pm 2 \%$ for the volumetric flow rate of the cooling water, and $\pm 2 \%$ for the heat flux measured by the heat flow meters. Following the uncertainty propagation analysis [16], the estimated uncertainties for the deduced experimental results were as follows: $5.1-26.2 \%$ for the heating flux, $3.1-25.8 \%$ for the cooling power, and $4.3-21.8 \%$ for the average $\mathrm{Nu}$.

\section{Results and Discussion}

This experiment mainly discusses the effects of the heating power, cooling section temperature Tc, and height difference between the hot and cold ends $\Delta \mathrm{Z}$ on the heat transfer phenomenon in a rectangular thermosyphon. The input thermal power is 30-60 W (the heating flux is in the range of $\left.600-3800 \mathrm{~W} / \mathrm{m}^{2}\right)$; Tc is 30,40 , or $50^{\circ} \mathrm{C}$, and $\Delta \mathrm{Z}$ is 5,11 , or $18(\mathrm{Lc}=60,45$, or $30 \mathrm{~cm}$, respectively).

Due to space limitations, only the experimental result of $\mathrm{Tc}=40^{\circ} \mathrm{C}$ is introduced; the heat flow phenomena for the other Tc values of $30{ }^{\circ} \mathrm{C}$ and $50{ }^{\circ} \mathrm{C}$ are similar to that of $\mathrm{Tc}=40{ }^{\circ} \mathrm{C}$ and are not discussed further. Figure 3 shows the change in working fluid (water) temperature in the loop at $\mathrm{Tc}=40^{\circ} \mathrm{C}$ as the thermal power increases. In the upper graphs, the $\mathrm{x}$-axis represents thermocouple measurement points from Channel 1 to Channel 8, and the y-axis is the fluid temperature in the loop. In the lower graphs, the $\mathrm{x}$-axis is experimental time.

Figure 3a shows the temperature variation of the working fluid (water) along the loop as a function of the heating power with a height difference $\Delta Z=5(\mathrm{Lc}=60 \mathrm{~cm})$. First, the fluid in the thermosyphon is close to the stationary state. When the thermal power is set to $30 \mathrm{~W}$, the temperature of the fluid in the heating section increases, and the fluid in the heating section slowly flows to the cooling section; it takes approximately $20 \mathrm{~min}$ to reach a steady state. Because the initial input of thermal power already initiated natural convection in the fluid in the thermosyphon, it only takes $5 \mathrm{~min}$ to reach a steady state after increasing the thermal power to $40 \mathrm{~W}, 50 \mathrm{~W}$, and $60 \mathrm{~W}$. When the thermal power is increased to $40 \mathrm{~W}$, the temperature of the fluid in the middle section of the heating section (Channel 2) oscillates. The possible reason may be that the temperature boundary layer growth in the heating section is accompanied by a temperature mixing phenomenon formed by the fluid turning at the bend (near the 
heating section inlet). This oscillating phenomenon becomes more pronounced as the thermal power increases for a height difference $\Delta \mathrm{Z}$ of 5 .
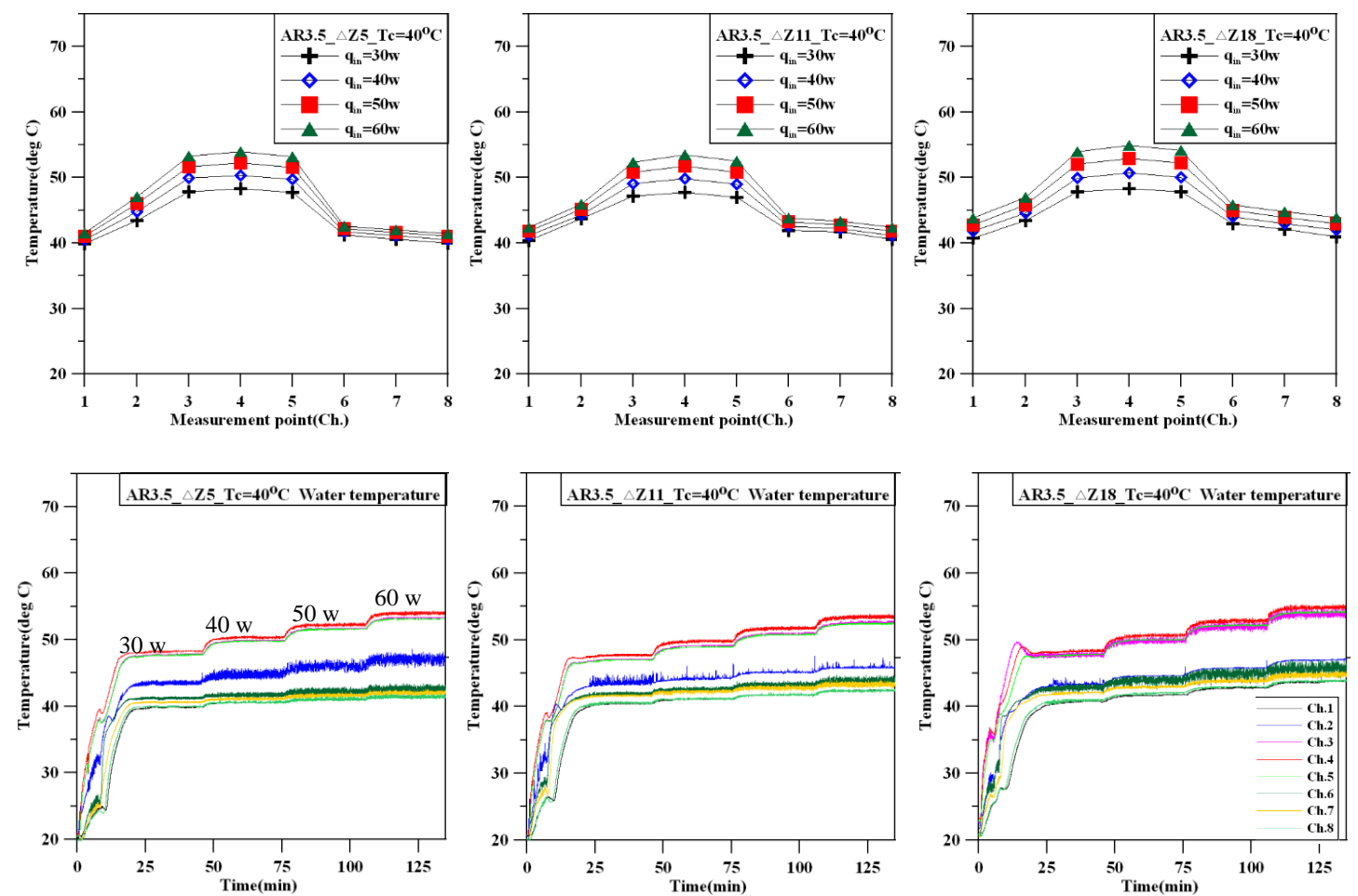

(b) $\Delta \mathrm{Z}=11$

(c) $\Delta \mathrm{Z}=18$

Figure 3. Fluid temperature variation along the loop as a function of the heating power $(\mathrm{AR}=3.5$, $\mathrm{TC}=40{ }^{\circ} \mathrm{C}, \Delta \mathrm{Z}=5,11$, and 18$)$.

Figure $3 \mathrm{~b}$ shows the temperature variation of the working fluid along the loop as a function of the heating power with a height difference $\Delta \mathrm{Z}$ of $11(\mathrm{Lc}=45 \mathrm{~cm})$. The temperature variation pattern of the fluid in the thermosyphon is similar to that of Figure 3a, and it takes approximately 20 min to initially reach a steady state. After that, with further increases in the thermal power, the steady state is reached in approximately $5 \mathrm{~min}$. The steady-state average temperature of the fluid in the thermosyphon shown in Figure $3 b$ is similar to that of Figure 3a. Additionally, after the input thermal power exceeds $40 \mathrm{~W}$, the temperature oscillation in the middle section (Channel 2) of the heating section begins to decrease. With increasing thermal power, the oscillation at Channel 2 becomes less noticeable. Figure $3 \mathrm{c}$ shows the temperature variation with the height difference $\Delta \mathrm{Z}$ of $18(\mathrm{Lc}=30 \mathrm{~cm})$. The temperature rise of the fluid in the thermosyphon is similar to the former two conditions, but the thermosyphon takes approximately $25 \mathrm{~min}$ to reach the initial steady state and approximately $5 \mathrm{~min}$ to reach new steady states when the heat power is increased.

Comparison of the three sets of data reveals that Figure 3c, with a larger $\Delta \mathrm{Z}$, has a higher average temperature (approximately $2{ }^{\circ} \mathrm{C}$ higher) after the steady state is reached. The temperature difference between the highest and lowest power in Figure $3 \mathrm{c}$ is slightly higher than in Figure 3a. Comparison of Figure $3 \mathrm{a}, \mathrm{b}$ with Figure $3 \mathrm{c}$ shows that when $\Delta \mathrm{Z}$ is larger (the length of the cooling section is shorter), fluid temperature oscillations were observed at the exits of both the heating section and the cooling section (Channel 3 and Channel 6). This oscillating phenomenon is more pronounced as the thermal power increases. However, as $\Delta \mathrm{Z}$ increases, the temperature oscillation magnitude in the middle section of the heating section (Channel 2) begins to decrease.

Figure 4 shows the change in temperature at each point in the outer wall of the thermosyphon as the thermal power increases. The temperature changes in each graph are quite similar. Due to the increase in heating power and the temperature rise of the fluid in the tube, the temperature of the outer 
tube wall at the end of the heating section is the highest. After entering the adiabatic section, the wall temperature of the outer tube wall decreases slightly. This phenomenon is mainly caused by the axial heat transfer of the tube wall. After entering the cooling section, the temperature of the outer tube wall begins to drop to Tc after cooling. However, after the cooling section, the temperature of the outer wall of the adiabatic section rises slightly due to the axial heat transfer. This temperature rise phenomenon is more obvious for $\Delta Z=18$ than for $\Delta Z=5$ and 11 .
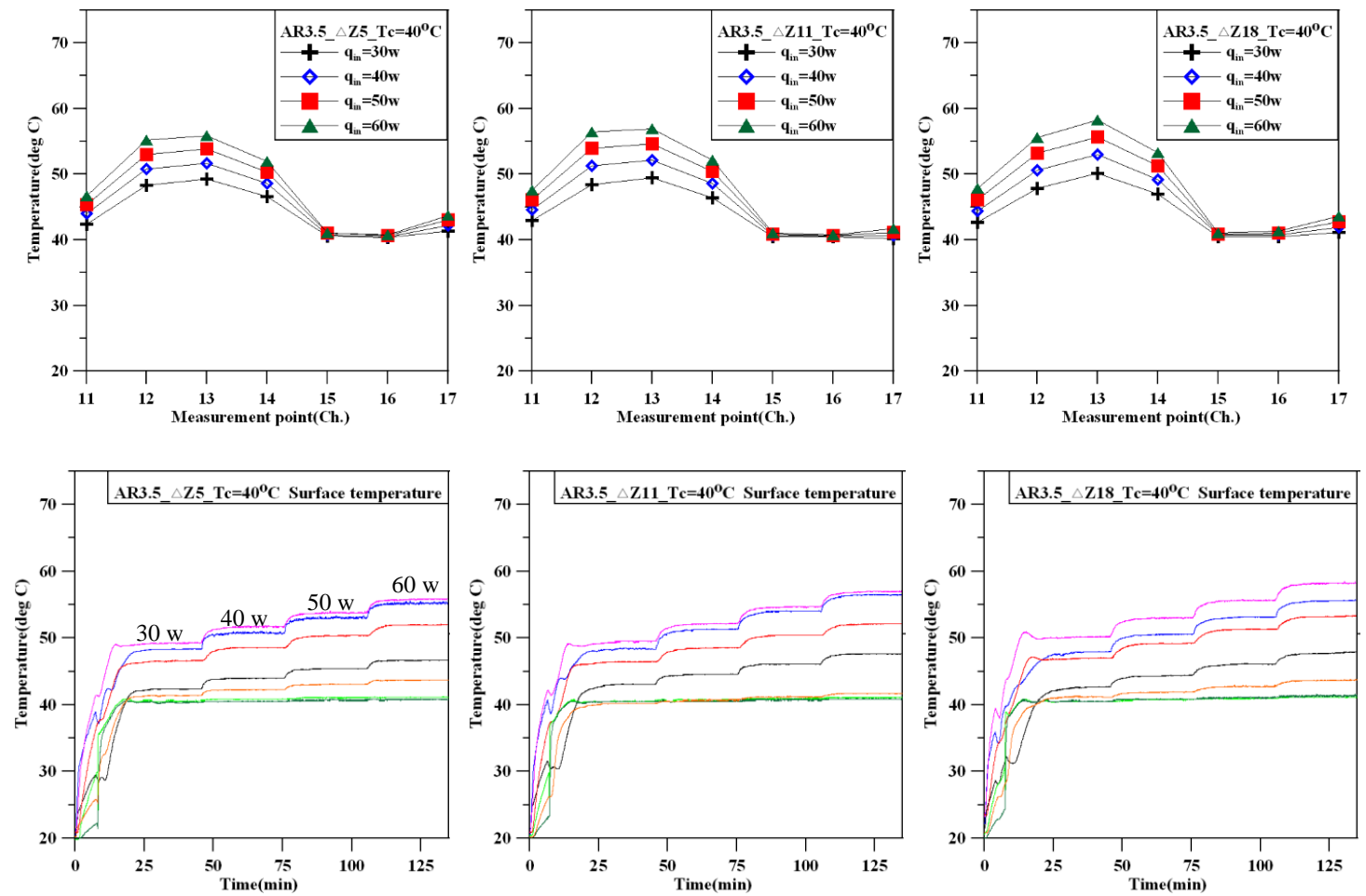

Figure 4. Exterior wall temperature variation along the loop as a function of the heating power.

Figure 5 shows the relationship between the $\mathrm{Nu}$ and the modified Rayleigh number $\left(\mathrm{Ra}^{*}\right)$ of the loop. Overall, the $\mathrm{Nu}$ is approximately $5-10$. As $\mathrm{Ra}^{*}$ increases, the natural convection intensity of the working fluid increases, so $\mathrm{Nu}$ increases. Under the designated geometrical configuration, the height difference between the cold and hot ends of the loop also affects the natural convection strength of the loop fluid. When the $\mathrm{Ra}^{*}$ is fixed, as the height difference $\Delta \mathrm{Z}$ increases, the $\mathrm{Nu}$ also increases. The effect of the cooling end temperature $\mathrm{Tc}$ on $\mathrm{Nu}$ is less significant. Therefore, if it is desired to increase the natural convection effect of the fluid in the tube, in addition to increasing the power of the heating section, the height difference between the hot and cold ends is also one of the controllable factors.
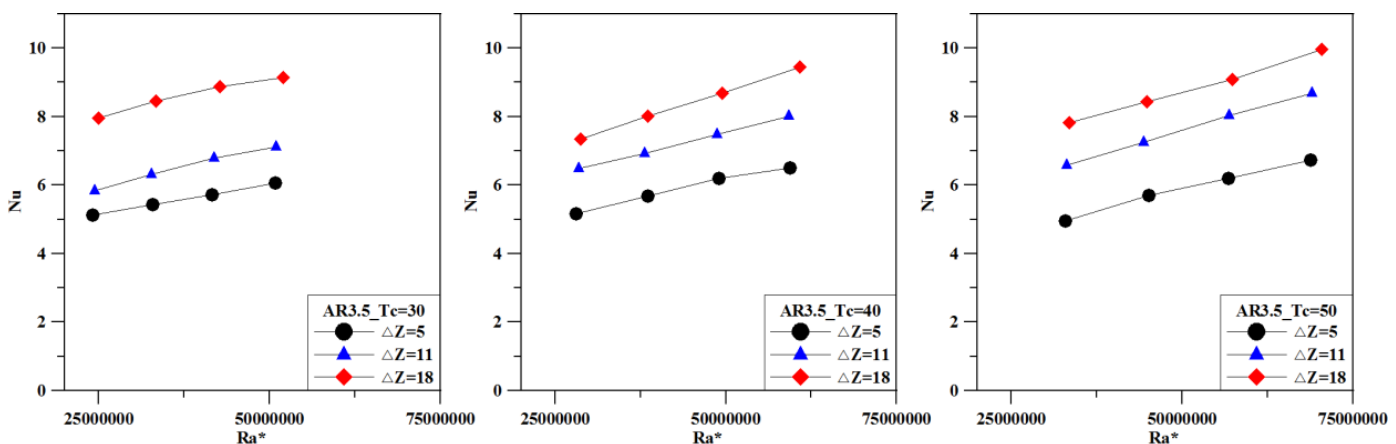

Figure 5. The relationship between the Nusselt number of loop flow and the modified Rayleigh number. 
Figure 6 shows the relationship between the average flow velocity of the fluid and the cold end temperature. As the heating power increases, the average flow rate of the fluid increases significantly. With the increase in Tc, the average flow velocity of the fluid increases slightly in conjunction with a high heating power but decreases slightly in conjunction with a low heating power. The overall variation pattern indicates that the average flow velocity of the fluid is less affected by the cold end temperature than by the heating power. As the length of the cold end increases, the overall average flow rate decreases slightly (Figure 7).
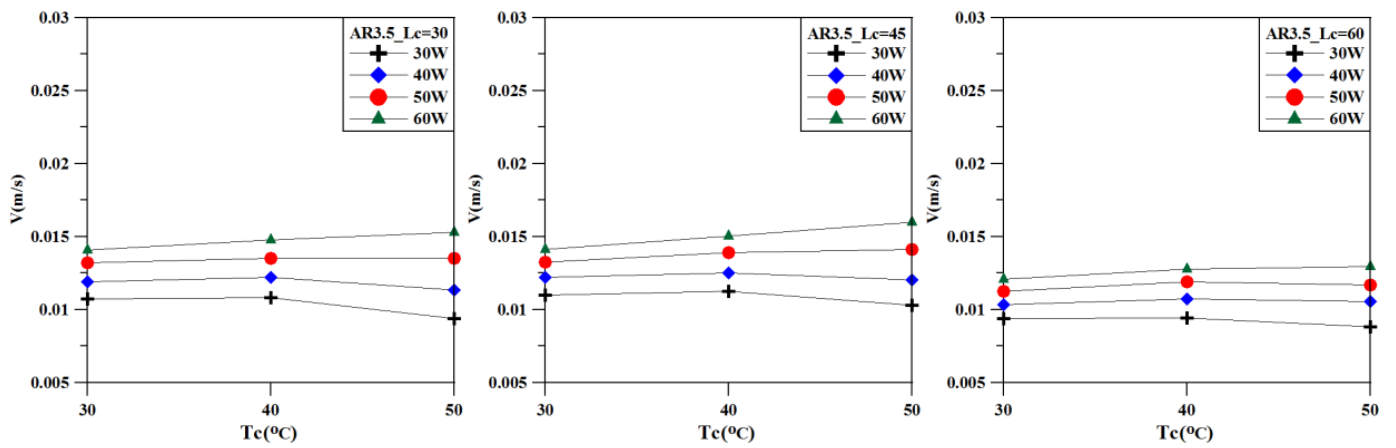

Figure 6. The relationship between average fluid velocity and temperatures of the cooling end Tc.
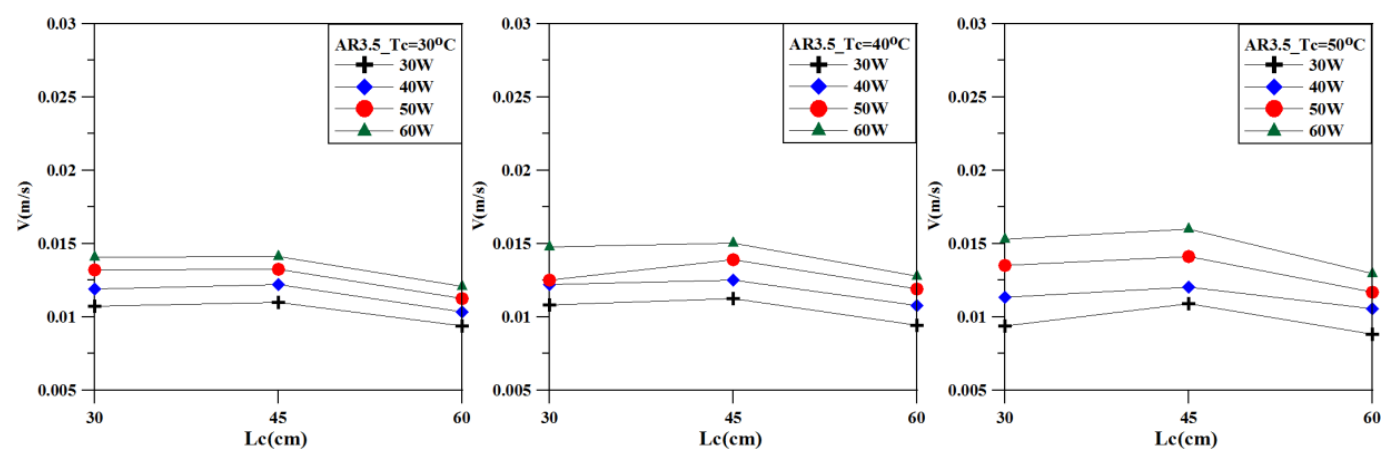

Figure 7. The relationship between the average fluid velocity and the length of the cooling end Lc.

Figure 8 shows the Re and heating power $\left(q_{i n}\right)$ of the fluid in the tube. When the input heating power is $30 \mathrm{~W}$, the Re values of the tube flow for different $\Delta \mathrm{Z}$ and Tc values are approximately 150-200. With an increase in the heating power or Tc, the Re increases, but the influence of heating power on the Re is more significant than that of Tc. Furthermore, the $\operatorname{Re}$ of $\Delta \mathrm{Z}=11$ is very close to that of $\Delta \mathrm{Z}=18$. A higher heating power, $\mathrm{Tc}$, or $\Delta \mathrm{Z}$ can result in higher fluid flow intensity. For $60 \mathrm{~W}, \mathrm{Tc}=50{ }^{\circ} \mathrm{C}$, and $\Delta Z=18$, the Re is approximately 345 .
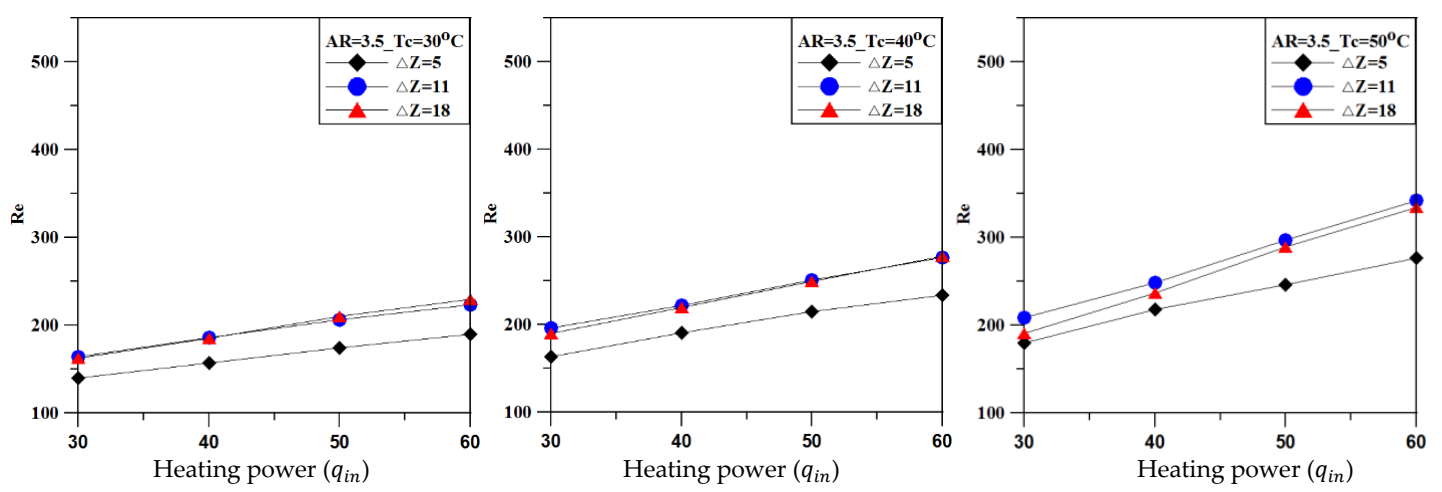

Figure 8. The relationship between the Reynolds number of pipe flow and heating power. 


\section{Conclusions}

The main purpose of this study is to investigate the heat transfer phenomenon of a rectangular thermosyphon with an aspect (height-to-width) ratio of 3.5 and a tube inner diameter of $11 \mathrm{~mm}$ using different heating powers, height differences between the heating and cooling ends, and cold end temperatures. From the experimental results, the following conclusions can be summarized:

1. The outer wall of the end of the heating section has the highest wall temperature. Due to the influence of axial heat transfer through the thermosyphon wall, the wall temperature of the outer tube decreases slightly after exiting the heating section (entering the upper adiabatic section); similarly, after exiting the cooling section, the wall temperature of the adiabatic section increases slightly.

2. A higher heating power or a larger height difference between the hot and cold ends can increase the fluid flow in the loop, whereas the cooling temperature has little influence.

3. Overall, the $\mathrm{Nu}$ is approximately $5-10$. If one wants to increase the natural convection effect of the fluid in the loop, in addition to increasing the heating power, the height difference between the hot and cold ends is also one of the controllable factors.

4. With a height difference of $\Delta \mathrm{Z}=5$ and a heating power of $40 \mathrm{~W}$, the temperature of the fluid in the middle heating section oscillates, and an increase in the heating power also increases the oscillations. For $\Delta Z=11$, the temperature oscillations in the middle heating section are reduced. For $\Delta Z=18$, fluid temperature oscillations are observed at the exits of both the heating and cooling sections; however, the water temperature in the middle heating section does not oscillate. The oscillation phenomenon may result from the mixing of fluid with different temperatures, which is caused by the growth of temperature boundary layers and turning of the flow at the loop elbows after the fluid is heated or cooled.

Author Contributions: C.S.H., R.H.C., and C.-M.L. conceived of and designed the model. C.S.H. and C.-W.Y. performed the experimental work. C.S.H., C.-W.Y., and C.-M.L. analyzed the data. C.-T.T. and C.-M.L. wrote the paper.

Acknowledgments: Support from the National Science Council of the ROC through grant No. NSC 100-2221-E-006-240-MY2 is gratefully acknowledged.

Conflicts of Interest: The authors declare no conflict of interest.

\section{Nomenclature}

A heating (or cooling) area $\left(\mathrm{m}^{2}\right)$

AR aspect ratio $\left(=\mathrm{L}_{\mathrm{y}} / \mathrm{L}_{\mathrm{x}}\right)$

Ch. position of the thermocouple

$C_{p} \quad$ specific heat capacity $(\mathrm{kJ} / \mathrm{kg} \mathrm{K})$

$\mathrm{D}_{\mathrm{i}} \quad$ inner diameter of the loop tube $(\mathrm{m})$

g acceleration due to gravity $(\mathrm{m} / \mathrm{s})$

$\bar{h} \quad$ average heat convection coefficient at the cooling end $\left(\mathrm{W} / \mathrm{m}^{2}{ }^{\circ} \mathrm{C}\right)$

I electric current (A)

k thermal conductivity of the working fluid $(\mathrm{W} / \mathrm{m})$

$\mathrm{L}_{\mathrm{c}} \quad$ length of the cooling end $(\mathrm{m})$

$\mathrm{L}_{\mathrm{x}} \quad$ width of the test cell $(200 \mathrm{~mm})$

$\mathrm{L}_{\mathrm{y}} \quad$ height of the test cell (=length of the heating end) $(700 \mathrm{~mm})$

$\mathrm{Nu} \quad$ Nusselt number

$q_{a} \quad$ axial heat conduction along the loop wall (W)

$q_{c} \quad$ heat transfer rate at the cooling section (W)

$q_{f l u x} \quad$ heat flux at the heating section $\left(=q_{h} / \mathrm{A}\right)$

$q_{h} \quad$ heating power (W) 


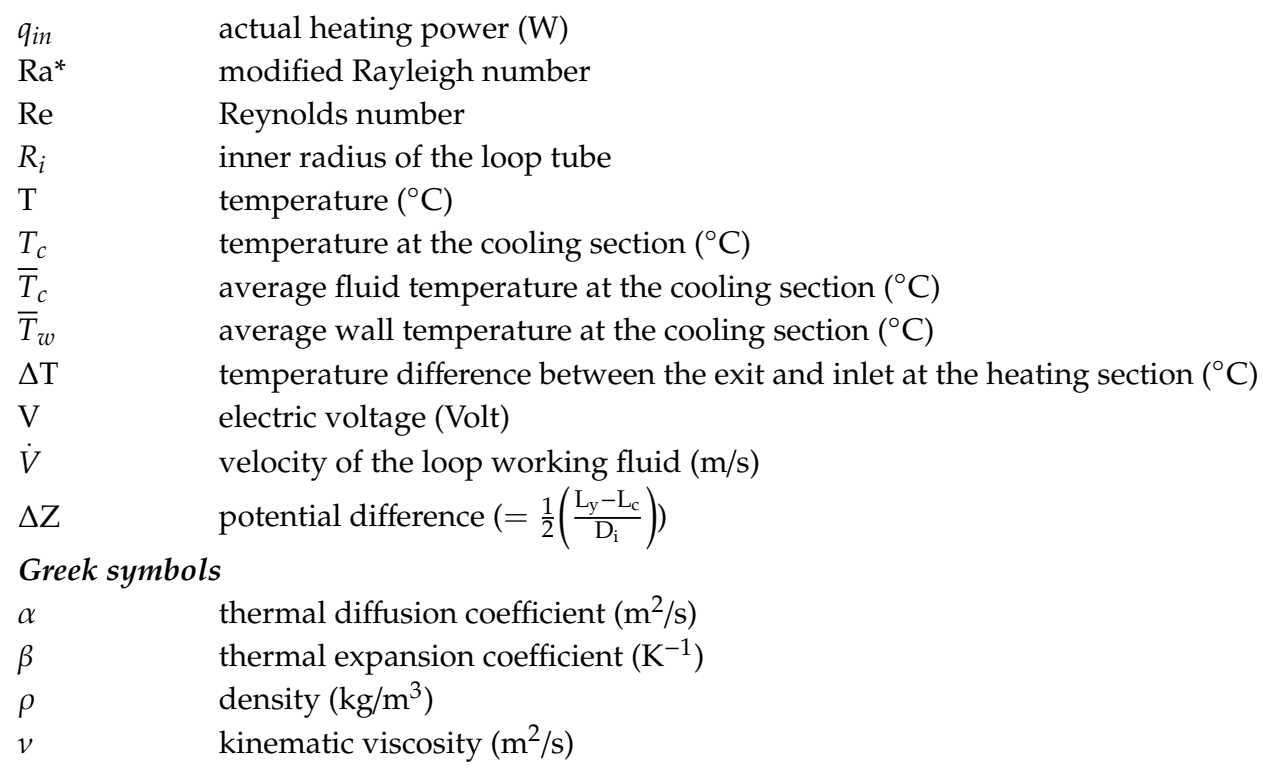

\section{References}

1. Garrity, P.T.; Klausner, J.F.; Mei, R. Instability phenomena in a two-phase microchannel thermosyphon. Int. J. Heat Mass Transf. 2009, 52, 1701-1708. [CrossRef]

2. Vijayan, P.K.; Sharma, M.; Pilkhwal, D.S.; Saha, D.; Sinha, R.K. A comparative study of single-phase, two-phase, and supercritical natural circulation in a rectangular loop. J. Eng. Gas Turb. Power 2010, 132, 102913. [CrossRef]

3. Misale, M.; Garibaldi, P.; Tarozzi, L.; Barozzi, G.S. Influence of thermal boundary conditions on the dynamic behaviour of a rectangular single-phase natural circulation loop. Int. J. Heat Fluid Flow 2011, 32, 413-423. [CrossRef]

4. Lai, C.-M.; Chen, R.-H.; Huang, C.S. Development and thermal performance of a wall heat collection prototype. Build. Environ. 2012, 57, 156-164. [CrossRef]

5. Delgado, M.; Lázaro, A.; Mazo, J.; Zalba, B. Review on phase change material emulsions and microencapsulated phase change material slurries: Materials, heat transfer studies and applications. Renew. Sustain. Energy Rev. 2012, 16, 253-273. [CrossRef]

6. Desrayaud, G.; Fichera, A.; Lauriat, G. Two-dimensional numerical analysis of a rectangular closed-loop thermosiphon. Appl. Therm. Eng. 2013, 50, 187-196. [CrossRef]

7. Buschmann, M.H. Nanofluids in thermosyphons and heat pipes: Overview of recent experiments and modelling approaches. Int. J. Therm. Sci. 2013, 72,1-17. [CrossRef]

8. Huminic, G.; Huminic, A. Numerical study on heat transfer characteristics of thermosyphon heat pipes using nanofluids. Energy Conversat. Manag. 2013, 76, 393-399. [CrossRef]

9. Sureshkumar, R.; Mohideen, S.T.; Nethaji, N. Heat transfer characteristics of nanofluids in heat pipes: A review. Renew. Sustain. Energy Rev. 2013, 20, 397-410. [CrossRef]

10. Gupta, N.K.; Tiwari, A.K.; Ghosh, S.K. Heat transfer mechanisms in heat pipes using nanofluids-A review. Exp. Therm. Fluid Sci. 2018, 90, 84-100. [CrossRef]

11. Ho, C.J.; Chiou, S.P.; Hu, C.S. Heat transfer characteristics of a rectangular natural circulation loop containing water near its density extreme. Int. J. Heat Mass Transf. 1997, 40, 3553-3558. [CrossRef]

12. Vijayan, P.K.; Sharma, M.; Saha, D. Steady state and stability characteristics of single-phase natural circulation in a rectangular loop with different heater and cooler orientations. Exp. Therm. Fluid Sci. 2007, 31, 925-945. [CrossRef]

13. Misale, M.; Garibaldi, P.; Passos, J.C.; de Bitencourt, G.G. Experiments in a single-phase natural circulation mini-loop. Exp. Therm. Fluid Sci. 2007, 31, 1111-1120. [CrossRef]

14. Swapnalee, B.T.; Vijayan, P.K. A generalized flow equation for single phase natural circulation loops obeying multiple friction laws. Int. J. Heat Mass Transf. 2011, 54, 2618-2629. [CrossRef] 
15. Thomas, S.; Sobhan, C.B. Stability and transient performance of vertical heater vertical cooler natural circulation loops with metal oxide nanoparticle suspensions. J. Heat Transf. Eng. 2018, 39, 861-873. [CrossRef]

16. Moffat, R.J. Using uncertainty analysis in the planning of an experiment. J. Fluid Eng. 1985, 107, $173-178$. [CrossRef]

(c)

(C) 2019 by the authors. Licensee MDPI, Basel, Switzerland. This article is an open access article distributed under the terms and conditions of the Creative Commons Attribution (CC BY) license (http://creativecommons.org/licenses/by/4.0/). 